\title{
Tramas argumentales en el debate legislativo sobre el aborto
}

\author{
Irma Mariana Gutiérrez Morales
}

Este artículo expone las tramas argumentales construidas por los legisladores del Distrito Federal en los debates que tuvieron lugar de noviembre de 2006 a abril de 2007 en la Asamblea Legislativa, a propósito de las reformas al Código Penal local propuestas para despenalizar el aborto. Después del análisis argumentativo de los debates en el pleno, en este trabajo intentan recrearse las interacciones discursivas entre los hablantes como parte de sus estrategias políticas, personales y colectivas. Se muestra cómo a partir del entramado argumentativo se justifican posturas y puntos de vista sobre el problema a discusión y cómo se establecen alianzas y confrontaciones entre los grupos parlamentarios.

PALABRAS CLAVE: aborto, argumentos, debate parlamentario, diputados, interrupción legal del embarazo, análisis del discurso

\section{Argumentative Plots in Legislative Debate on Abortion}

This paper reports the argumentative plots built by local legislators in the debates that took place from November 2006 to April 2007 in the Legislative Assembly of the Federal District, Mexico, concerning of local Penal Code reforms, proposed to decriminalize abortion. After the argumentative analysis of the debates in plenary, it is intended to recreate the discursive interaction among speakers, as part of their political strategies, personal and collective. It shows how positions and points of view on the issues discussed are justified by argumentative plots, and how alliances and confrontations are established among the parliamentary groups.

KEYWORDS: abortion, arguments, parliamentary debates, deputies, legal pregnancy interruption, discourse analysis

Irma Mariana Gutiérrez Morales: Facultad de Estudios Superiores Acatlán, Universidad Nacional Autónoma de México,

Naucalpan, Estado de México, México

mariana_gmx@yahoo.com

Desacatos, núm. 43, septiembre-diciembre 2013, pp. 67-84

Recepción: 8 de marzo de 2012 / Aceptación: 22 de julio de 2012 


\section{INTRODUCCIÓN}

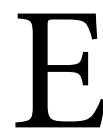
$\mathrm{n}$ abril de 2007, luego de cinco meses de debates sobre la despenalización del aborto en la Asamblea Legislativa del Distrito Federal (ALDF), fueron aprobadas reformas al Código Penal local para permitir la interrupción legal del embarazo durante las primeras 12 semanas de gestación. A pesar de que la legislación de la ciudad de México ya admitía cuatro causales para la despenalización del aborto - por imprudencia de la mujer embarazada, por violación, por peligrar la salud de la mujer o por alteraciones congénitas del producto-, lo novedoso, que desató la controversia a nivel nacional, era que con estas reformas se pretendía flexibilizar al máximo la ley para permitir el aborto a solicitud de la mujer embarazada cualesquiera que fueran sus razones.
A pesar de que la discusión llegó a diversos escenarios a nivel nacional, el análisis que se presenta en este artículo corresponde a los debates que sostuvieron los legisladores locales en el periodo comprendido entre noviembre de 2006, cuando se propusieron las reformas ante el pleno de la Asamblea, hasta abril de 2007, fecha en que se deliberó y votó el dictamen. Se pretende mostrar cuáles fueron los objetos discursivos predominantes en la argumentación general, cómo se tejieron tramas argumentales para justificar las posturas de los grupos parlamentarios y cómo se manifestaron alianzas y confrontaciones a partir de la configuración lingüística y argumentativa de los oradores. Como en todo discurso político, en los textos que conformaron el corpus - versiones estenográficas de los debates en la Asamblea- la ideología y las distintas nociones de poder fueron determinantes para la construcción de ciertas

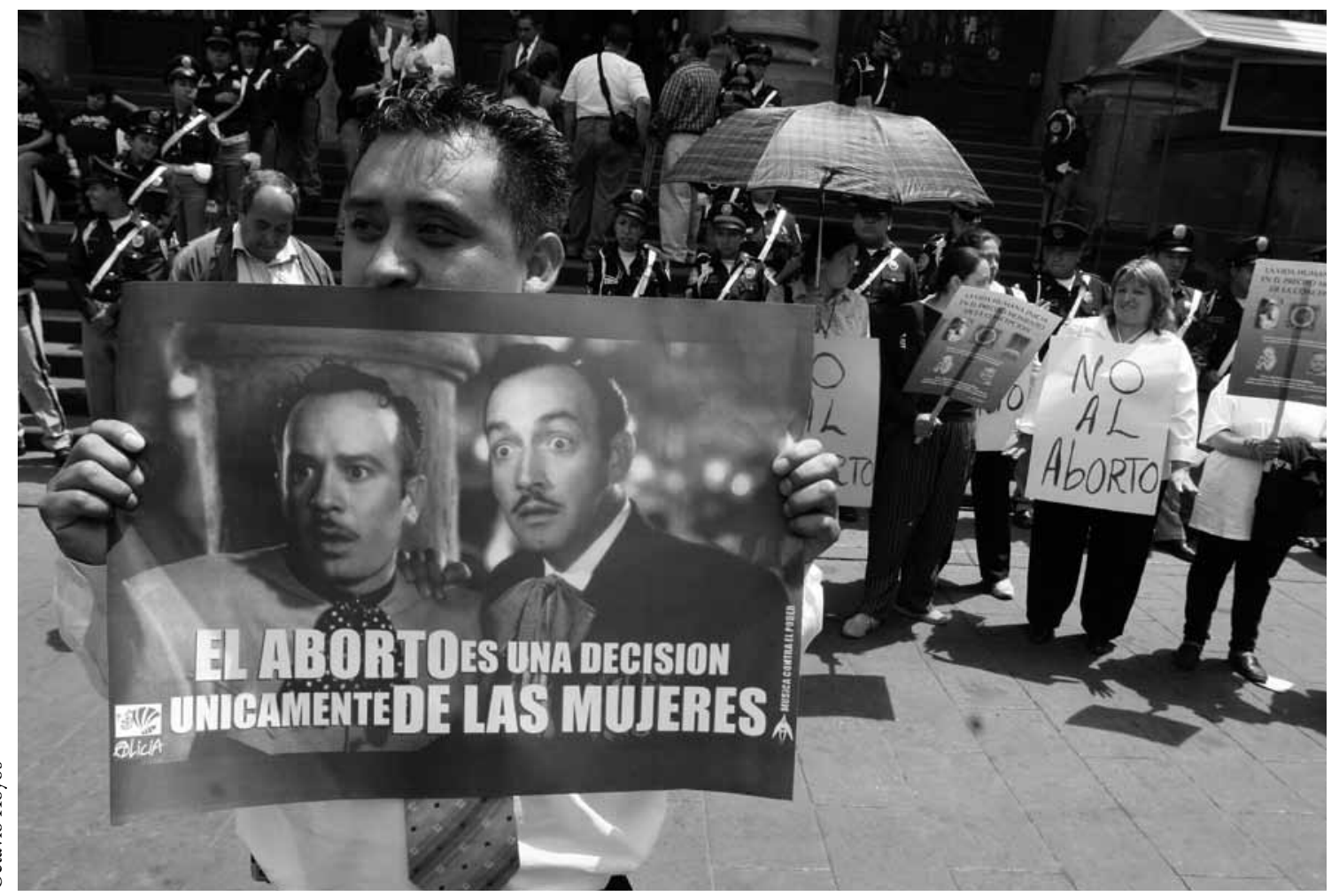

Asamblea Legislativa del Distrito Federal durante el debate sobre la interrupción legal del embarazo, 2007. 
representaciones de la realidad que los hablantes propusieron con sus discursos (Giménez, 2008), lo mismo que para elegir la forma de acceder estratégicamente a ciertos órdenes simbólicos y con ello afianzar una postura e intentar mantener o modificar una situación de poder.

Además, es necesario tomar en cuenta que estos discursos provinieron de la escena parlamentaria, de tal suerte que se encontraban definidos no sólo por las reglas y procedimientos formales a los que deben constreñirse los hablantes, sino por las condiciones socioculturales y políticas características de su efectuación. En cuanto a los procedimientos formales nos referimos al intercambio de turnos, a la extensión prefijada de los discursos, a la aceptación de ciertos cargos y atribuciones de las autoridades legislativas, al apego a las tareas parlamentarias previamente establecidas e incluso a un cierto estilo de enunciación, aspectos que - asumidos por los legisladores - marcaron de forma adyacente los discursos en la búsqueda de la autolegitimación de los actores políticos y de la legitimación de sus propias palabras. Aunque ciertamente no es inusual la transgresión recurrente de dichas reglas en el quehacer parlamentario (Carbó, 1996). Retomar estos elementos en el análisis resultó de vital importancia para poder ofrecer una interpretación que condujera a determinar estrategias, tanto de orden discursivo como de orden político.

\section{PLANTEAMIENTO TEÓRICO-METODOLÓGICO}

El análisis del discurso engloba una serie de procedimientos heterogéneos orientados a determinar tanto la organización y el sentido del material verbal, es decir, el uso de la lengua, como la manera en que las producciones verbales están ligadas a condiciones de producción, situaciones de comunicación y proyectos de los sujetos enunciadores (Pêcheux, 1978). En este trabajo se practicó un análisis argumentativo que permitiera identificar la forma en que los hablantes construyeron el sustrato discursivo que apoyó sus tesis y la manera en que tejieron con el material verbal una serie de estrategias orientadas a lograr un objetivo evidentemente político. Se pretendió desentrañar las tesis, los argumentos y los entrecruzamientos de los discursos derivados de la interacción de los hablantes y de su pretensión de apoyarse o confrontarse en el espacio político, así como de intervenir y condicionar a través de pruebas - discursivas, por supuesto- a un auditorio (Grize, 1990: 15-16), pruebas no necesariamente verdaderas, pero sí sólidas y verosímiles.

Múltiples son los caminos que pueden seguirse para el hallazgo y posterior descripción de las estrategias argumentativas que subyacen en los discursos. Si bien asumimos una postura ecléctica que, como señala Salgado (2003: 46), nos permitiera aproximarnos a la necesidad de diseccionar el habla para "desandar el camino" y llevarnos a las condiciones de su producción, evidentemente sobresale un enfoque lógico discursivo como propuesta para reconstruir los sentidos y estrategias discursivas globales y, con ello, las operaciones de pensamiento lógicas y retóricas que se materializaron en los discursos. Nos basamos en la reconstrucción de los objetos discursivos y sus predicaciones como sustrato de los argumentos, pero sobre todo en la identificación de relaciones entre argumentos que ponen en evidencia las estrategias argumentativas globales de los discursos. Georges Vignaux ([1976] 1986) propone un camino para rastrear operaciones de pensamiento de los sujetos enunciadores, mismas que resultan una evidencia empírica valiosa que enlaza lo cognitivo con lo lingüístico. También es importante la manera en que contempla el discurso desde su funcionamiento sociocognitivo, vinculado a la ubicación del hablante y las determinaciones exteriores del discurso:

a partir de una ubicación determinada del hablante en el seno de una formación social, señala una posición de ese hablante acerca de un tema o de un conjunto de temas, posición que refleja de manera directa, no directa, o incluso disfrazada la ubicación 
del hablante en la formación social considerada (Vignaux, [1976] 1986: 66).

El interlocutor juega un papel trascendente en la configuración del discurso del hablante como referencial delimitativo:

es ese otro quien determina las proposiciones del discurso pues a él apuntan las aserciones o los juicios vinculados por el hablante en un sistema delimitado por los usos de composición oratoria, sistema señalado a la vez por la dinámica discursiva (reglas propias de la institución del discurso) y por la estructuración de un pensamiento que el hablante quiere transmitir (Vignaux, [1976] 1986: 66).

De lo anterior retomamos para el análisis que dado que el texto es producto de circunstancias exteriores, éstas determinan el énfasis y la selección de las ideas - objetos discursivos-. Que a partir de esta relación del lenguaje con el exterior, de un exterior del que se abstraen características, se eligen criterios
Por el contrario, una estrategia de ese orden se arma a partir de movimientos, de relaciones, de vínculos entre argumentos. El hablante cauteloso, como se concibe al actor político, sabe que gran parte de la eficacia de un discurso descansa en la conexión entre argumentos, ya sea al formar cadenas en las cuales unos complementen a otros, se continúen, se apuntalen mutuamente, o bien al oponerlos al alimentar la controversia, al tratar de socavar la fuerza argumentativa de las proposiciones de su adversario. Es por ello que una vez identificados los argumentos de los discursos proponemos intentar establecer relaciones sucesivas entre ellos. Dichas relaciones, que son a la vez indicativas de operaciones de pensamiento del hablante, pueden ser de incompatibilidad, consecuencia, implicación, oposición, complementación, equivalencia, diferencia, unión, jerarquía; relaciones que nos permiten identificar tramas argumentales.

Entendemos por tramas argumentales las relaciones recíprocas entre los argumentos de los oradores participantes en el debate. Como estrategia personal del hablante en su desenvolvimiento argumentativo, éste puede configurar su discurso basado en un argumento $X$, y más adelante, en el discurrir del debate, modificarlo por un $X^{\prime}$-al añadir ciertos componentes, predicaciones, no contemplados al principio-, por un $-X-$ al elegir el mismo objeto discursivo pero predicado de manera radicalmente distinta, incluso negando la predicación previamente construida-, por un $Y$ - al seleccionar otro objeto discursivo como sustento de la tesis-, o bien, abandonar definitivamente su argumento original. En las tramas argumentales lo que está en juego son estrategias colectivas o personales que se entretejen dentro de una red argumental en la que cada punto del discurso va formando vínculos con otros puntos, por lo regular de complementación entre partidarios y de oposición entre adversarios. Cabe aclarar que para el análisis sólo consideramos los argumentos que Vignaux llama "pivotes" y que son aquellos que por su frecuencia en los discursos se convierten en marcadores relevantes de la mente al contenido proposicional de los mismos. 
estrategia semántica-conceptual de los mismos y que no pueden faltar sin que se desmorone la estructura lógica del discurso (Gutiérrez, 1989: 18).

\section{RESULTADOS}

Los discursos que conformaron el corpus, por lo general, explicitan la imbricación que deviene de los vínculos entre idearios, propósitos y situaciones comunicativas, políticas y, por supuesto, discursivas, establecidos en el acto de habla y asumidos por los propios oradores. Para mostrar estas operaciones lógicas hemos optado por describirlas en función de la manera en que diseña el escenario de interacción política entre los legisladores: los momentos de apoyo y los de enfrentamiento en que se ven implicados los participantes y que provienen del funcionamiento lógico de los discursos y de la sucesión de turnos de habla.

\section{a) Los diputados se apoyan}

El debate en la Asamblea giró en torno a, por una parte, la proposición de argumentos que respaldaran la aprobación de una reforma al Código Penal local para despenalizar el aborto practicado antes de las 12 semanas de gestación y a solicitud de la mujer embarazada, sin importar los motivos que tuviere para ello. Por otra parte, se incorporaron argumentos, o mejor dicho contraargumentos, cuyo propósito era desestimar la aprobación de la reforma. Después del análisis del corpus se aprecia un tejido proposicional que en determinados momentos se hace más denso por la invocación y predicación constante de ciertos objetos discursivos y por la continua vinculación entre pares de argumentos que se complementan, implican, oponen, excluyen y diferencian. Estas imbricaciones delinean un mapa con distintos grados de saturación y al mismo tiempo marcan la emergencia de alianzas y confrontaciones entre los oradores. El señalamiento de alianzas se aprecia en la construcción de proposiciones complejas derivadas de predicaciones múltiples sobre un mismo objeto discursivo, entre las cuales se configuran relaciones de complementación e implicación principalmente. Esto es, un legislador propone un argumento y posteriormente él mismo o legisladores de grupos parlamentarios con los que se mantienen afinidades ideológicas o con los que se comparte una misma postura política lo complementan según la línea argumentativa inicial y hacen explícita con ello la manifestación de cierto apoyo discursivo y político.

Entendemos por relación de complementación la adición de argumentos a uno previo que ofrecen detalles no expuestos en la formulación original y que sirven como un reforzamiento del argumento inicial. Así, algunas de las variadas predicaciones de los objetos discursivos "aborto", "asamblea", "criterio de 12 semanas", "derechos del concebido", "despenalización del aborto", "mujeres", "pensamiento liberal" y "referéndum" son complementarios. Al ser la relación de complementación una manifestación de apoyo entre oradores, conocer entre qué grupos parlamentarios se entablan este tipo de relaciones es indicativo de estas estrategias políticas. Este tipo de asociación lógica se establece con las siguientes frecuencias entre: a) legisladores de un mismo grupo parlamentario: siete complementaciones; b) legisladores de los grupos parlamentarios de la Corriente de Socialismo Democrático (CSD) del Partido de la Revolución Democrática (PRD) y del Partido Revolucionario Institucional (PRI): tres complementaciones; c) y legisladores de los grupos parlamentarios del Partido Acción Nacional (PAN) y del Partido Verde Ecologista de México (PVEM): tres complementaciones. Los bloques - unión de dos o más grupos parlamentarios- se conforman por criterios políticos y se consolidan en el voto de los legisladores, pero lo interesante es confirmar que los bloques se mantienen en la estructuración lógica de los discursos. Como se aprecia en los incisos, el apoyo dado por las relaciones de complementación permite diferenciar la división de los grupos parlamentarios 
en dos bloques: los promotores - CSD, PRD y PRI- y los opositores de la reforma - PAN y PVEM-. Para ilustrar lo antes expuesto presentamos casos de construcciones argumentativas complementarias sobre algunos objetos discursivos:

a) Entre legisladores de un mismo grupo parlamentario:

- Objeto discursivo: "Criterio de 12 semanas" (PRD) El criterio de 12 semanas satisface un criterio de razonabilidad, pues permite una diferenciación cualitativa en el desarrollo gestacional / (PRD) La mortalidad materna es extremadamente baja en el primer trimestre de la gestación (COMP). ${ }^{1}$

b) Entre los promotores de la reforma:

- Objeto discursivo: "Despenalización" (CSD) La despenalización es un mecanismo para reconocer derechos sexuales y reproductivos de las mujeres / (PRD) Es un asunto de libertades que implica la autodeterminación de la mujer para elegir convertirse en madre (COMP).

c) Entre los opositores a la reforma:

- Objeto discursivo: "Aborto"

(PVEM) El aborto deja secuelas físicas y psicológicas / (PAN) Algunas de ellas son: necesidad de transfusión de sangre, perforación del útero, paro cardiaco, cirugía mayor, convulsiones, laceración cervical, ruptura uterina y muerte (COMP).

Nótese que los objetos discursivos que se refuerzan con la complementación adquieren un énfasis

\footnotetext{
${ }^{1}$ Utilizamos la nomenclatura que Vignaux expone en la $\mathrm{La}$ argumentación. Ensayo de lógica discursiva, basada en el Sistema M de Von Wright (Vignaux, [1976] 1986: 282). Añadimos antes de las predicaciones el grupo parlamentario que la enuncia (entre paréntesis). La barra entre argumentos significa el establecimiento de cierto tipo de relación entre ellos, que se especifica en el paréntesis final, según el siguiente listado: COMP=Complementación; $\mathrm{IMP}=$ Implicación; $\mathrm{C}=$ Consecuencia; $\mathrm{E}=$ Equivalencia; $\mathrm{D}=$ Diferencia; $\mathrm{J}=$ Jerarquía, $\mathrm{y} \mathrm{OP}=$ Oposición.
}

importante para argumentar una postura política. Así, los promotores hacen hincapié, por ejemplo, en el objeto "despenalización", y los opositores en "aborto", al que califican con atributos negativos.

Otro tipo de relaciones que explicitan acuerdos o connivencias entre los oradores son las implicaciones. Según los lógicos, esta relación está representada en la construcción "si $x$, entonces $y$ ". Traducida a la acepción común, la implicación expone una propiedad, circunstancia o fenómeno derivados de la naturaleza o identidad del objeto/predicación considerados. Este tipo de relación se aprecia igualmente en argumentos de legisladores de un mismo grupo o bloque parlamentario. En ese sentido, la implicación es tanto una estrategia de construcción silogística del argumento que refuerza el aparente carácter lógico racional del mismo como un mecanismo de vinculación del tejido discursivo que se gesta en el debate entre los distintos grupos. La recurrencia de este tipo de relación es semejante a la expuesta anteriormente y se presenta alrededor de los siguientes objetos: "aborto", "democracia”, "derechos del concebido", "derechos sexuales y reproductivos", "laicidad", "referéndum", "verdaderas soluciones" y "vida", con las siguientes frecuencias: a) ocho entre diputados del mismo grupo parlamentario; b) cuatro entre diputados del bloque promotor de la reforma (CSD, Panal, PRD, PRI); c) dos entre diputados del bloque opositor de la reforma (PAN, PVEM), d) una entre diputados del bloque promotor y del PVEM.

Hay que señalar que al bloque promotor se suma el grupo parlamentario del Partido Nueva Alianza (Panal) y que el PVEM participa en la construcción de implicaciones con ambos bloques. Básicamente son la CSD y el PAN los que construyen implicaciones desde la individualidad partidaria y con marcado carácter ideológico. Por ejemplo, para la CSD, la negación del ejercicio de los derechos sexuales y reproductivos de las mujeres, vía la penalización del aborto, implica la manifestación de violencia institucional y una ofensa a la dignidad humana. Este grupo parlamentario sostiene además que la realización del referéndum implica una visión patriarcal y una 


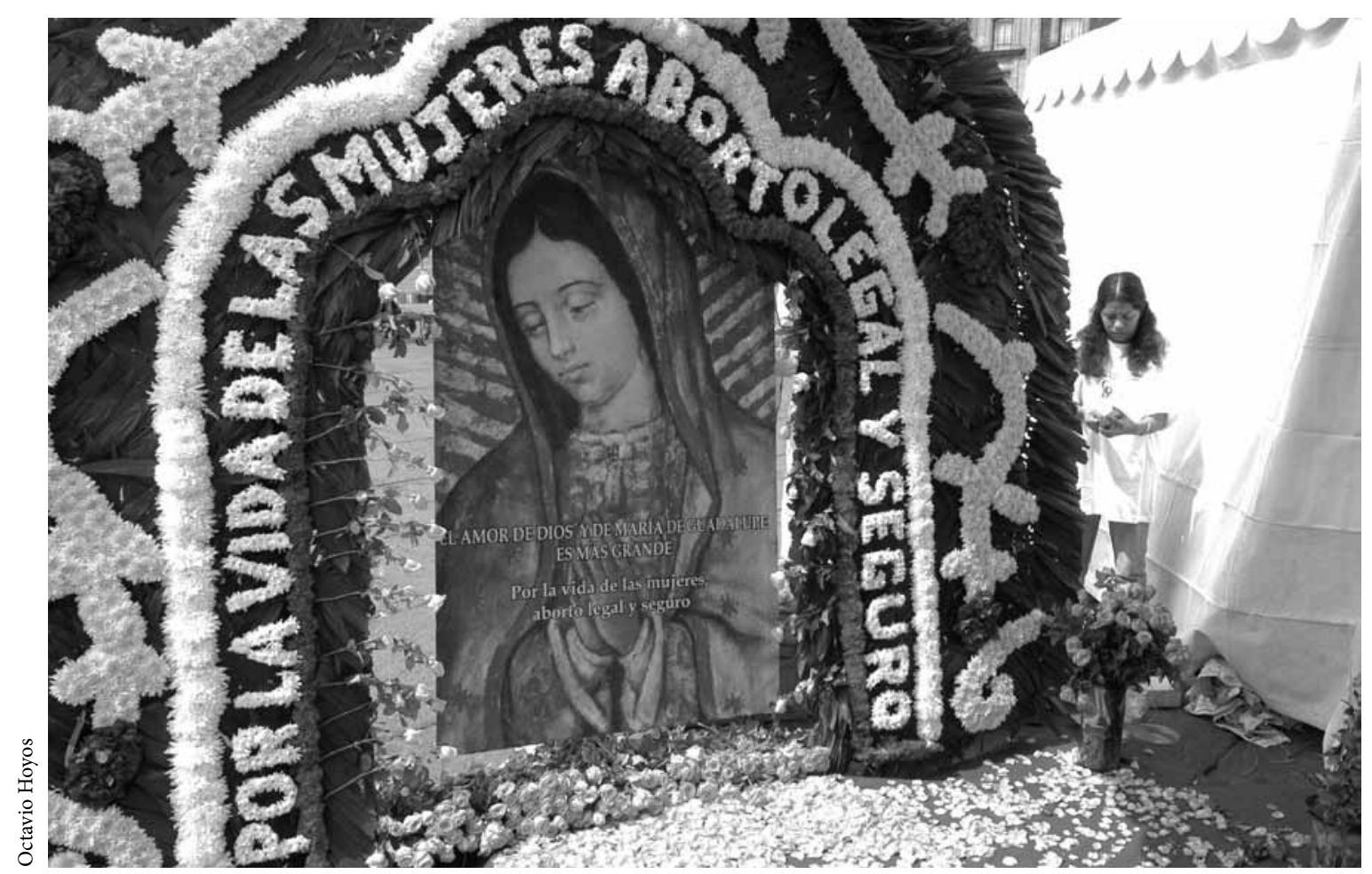

Católicas a favor del aborto, 2007.

exclusión de las minorías. Por su parte, el PAN expresa que la democracia implica la participación ciudadana en las decisiones legislativas - con lo que intenta legitimar la realización del referéndum- y que la existencia de una protección jurídica del concebido implica la inconstitucionalidad de una reforma que la rechace. Como bloque promotor de la reforma - diputados de los grupos parlamentarios de la CSD, Panal, PRD y PRI-, las implicaciones constituyen una validación racional de la despenalización del aborto en cuatro sentidos: 1) la despenalización como mecanismo para fortalecer la laicidad y la democracia del Estado mexicano; 2) la modificación de las estructuras sociales y de comportamiento de los ciudadanos; 3) la necesidad de reformas en materia de salud para garantizar el ejercicio pleno y seguro del aborto, y 4) el impulso de la educación sexual desde las instituciones educativas y de salud como verdadera solución al tema del aborto. En este último punto el PVEM se suma en apoyo al argumento. En otro orden de ideas, los opositores a la reforma - diputados de los grupos parlamentarios del PAN y del PVEM- se unen en la reiteración de dos argumentos: 1) la existencia de vida en el útero femenino antes de las 12 semanas de gestación, y 2) la creación de políticas públicas que protejan la maternidad para abatir el número de abortos que se practican.

\section{b) Los diputados intentan disuadirse}

El siguiente tipo de asociación entre argumentos que aparece en el corpus es la consecuencia. Esta relación establece la direccionalidad de un suceso, hecho o fenómeno hacia otro. La existencia del segundo de ellos sólo devendrá en la medida en que el otro, asimilado como la causa, tenga efecto. Es 
interesante que la incorporación de relaciones de consecuencia en los discursos tenga un carácter fundamentalmente disuasivo, en el sentido de que las que se exponen alrededor de ciertos hechos o fenómenos son por lo general negativas, con lo que se pretende que los adversarios desistan de algunos argumentos o por lo menos que el lado negativo de ciertos conceptos adquiera prominencia. De las diez construcciones que guardan relación de consecuencia encontradas en el corpus, ocho ocurren en esa dirección, como se muestra en los siguientes casos:

- Objeto discursivo: "Aborto"

(CSD/PRD/PRI) Complicaciones de abortos mal practicados / (CSD, PRD/PRI) Muerte materna (C).

(CSD/PRD) Mujeres sin recursos suficientes / (CSD/ PRI) Mayor exposición a los riesgos de la práctica fuera de las normas de salud (c).
- Objeto discursivo: "Derecho a decidir"

(PAN) Desavenencias en el matrimonio sobre la decisión de abortar / (PAN) Posibles divorcios (c).

En sentido positivo, sólo se detectan dos construcciones, ambas por parte del grupo parlamentario de la CSD. En una de ellas se plantea que el enfoque trimestral reduce los riesgos a la salud de las mujeres y que es ésta la razón por la cual este criterio es adoptado en varios países europeos. En la otra se reconoce que como consecuencia del servicio de aborto legal en algunos países se registran menos muertes relacionadas con embarazos y niveles menores de infanticidios y de abandono de infantes. En el mismo tenor aparecen relaciones de equivalencia. Este tipo de relación permite construir analogías que otorguen el mismo peso o sentido a dos hechos o fenómenos y que, por tanto, impliquen una

Gráfica 1. Relaciones lógicas entre argumentos

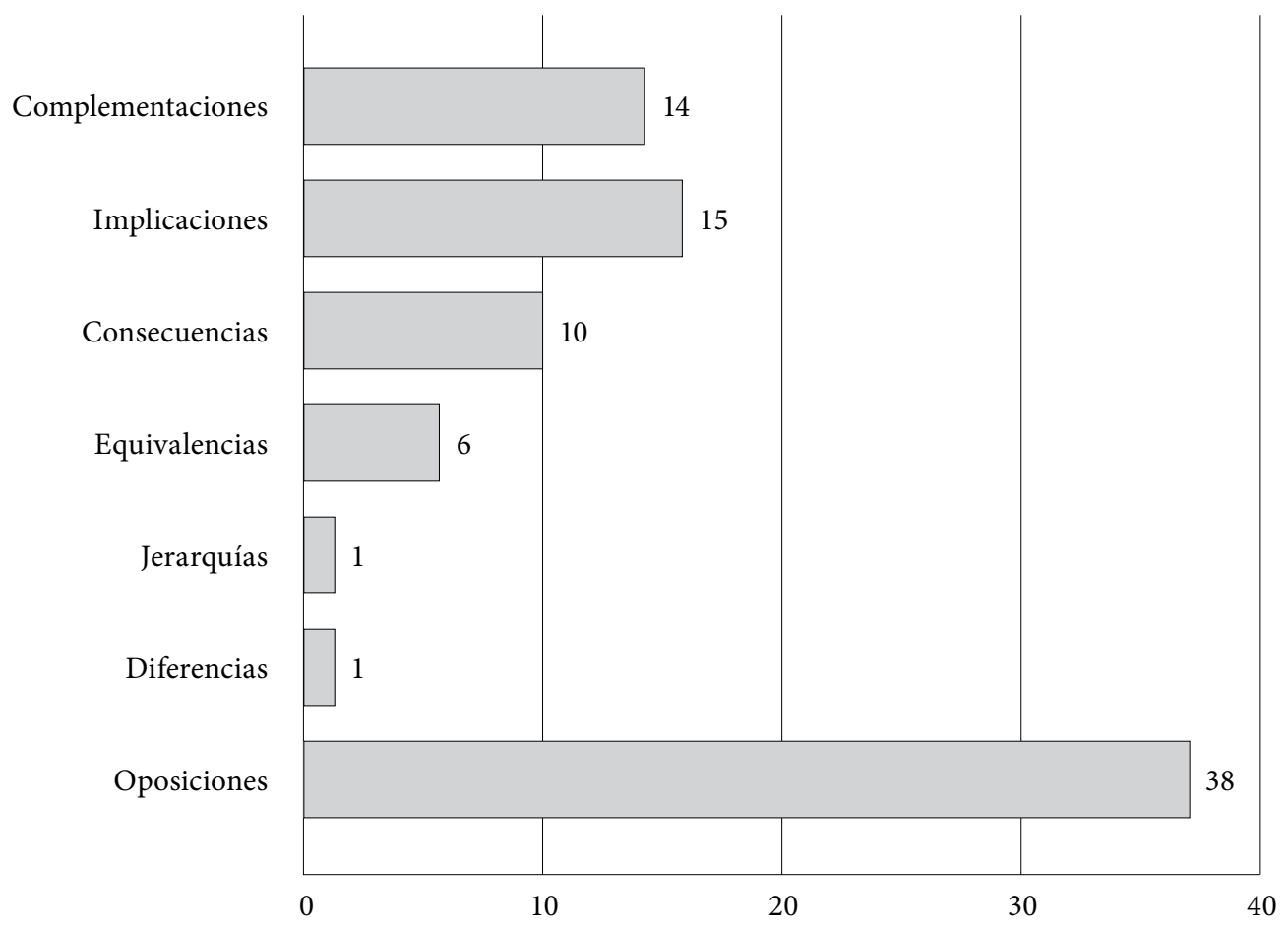

Fuente: Elaboración propia. 
comparación. Dos objetos son equivalentes cuando producen los mismos efectos o tienen consecuencias similares dadas las propiedades semejantes que el sujeto les atribuye. Las equivalencias encontradas en el corpus siguen la misma lógica que las consecuencias en su carácter disuasivo pues, por lo general, los oradores hermanan un asunto que está sometido a discusión en el pleno con otro que puede ser considerado como negativo. Al definir un objeto negativamente se intenta disuadir a los adversarios y a los terceros destinatarios de su apoyo a dicho objeto. De las seis construcciones de equivalencia entre argumentos pivote que se registran en el corpus, cuatro son de este tipo:

- Objeto discursivo: "Despenalización/nuevo tipo penal"

(PAN/PVEM) Modificar del tipo penal [la definición] del aborto para resolver un problema público I (PAN/PVEM) Corremos el riesgo de que el día de mañana en aras de abatir los índices de seguridad que padecemos en la ciudad, se intente por ejemplo cambiar la definición de robo u homicidio (E).

- Objeto discursivo: "Penalización del aborto" (PRD) Leyes que criminalizan el aborto / (PRD) Leyes discriminatorias y que atentan contra el derecho de la igualdad de las mujeres (E).

- Objeto discursivo: "Referéndum"

(PAN) Dar la espalda al referéndum / (PAN) Dar la espalda a la ciudadanía (E).

De esta manera se aprecia cómo los opositores presentan como equivalentes la despenalización del aborto como delito y la despenalización del homicidio o del robo, así como el rechazo al referéndum y la negación de la participación ciudadana. Mientras que para los promotores crear leyes que criminalizan el aborto equivale a aprobar leyes que discriminan a las mujeres y les niegan el ejercicio de sus derechos. Un caso especial es el del objeto "conflicto de derechos". Aunque en cierto momento ambos bloques, promotores y opositores de la reforma, afirmaron que tanto el derecho a decidir de las mujeres como el derecho a la vida del concebido tienen igual jerarquía, es decir, son equivalentes, esta postura no fue constante en el desarrollo de todo el debate, pues en tanto los promotores establecieron que el objetivo del dictamen era fortalecer y hacer prevalecer los derechos de las mujeres - en particular el derecho a decidir-, los opositores constantemente apoyaron la primacía de la vida como derecho sobre la libertad de decisión. Es entonces cuando aparece la relación de jerarquía, que marca una diferencia cualitativa entre dos objetos que se están comparando - a uno de ellos se le considera superior en términos de importancia, de alcance o de rol respecto del otro- y que en el caso del bloque opositor se construye de la siguiente manera:

- Objeto discursivo: "Conflicto de derechos"

(PAN/PVEM) Derecho a la vida, primero y superior / (PAN/PVEM) Derecho a decidir, supeditado al derecho a la vida $(\mathrm{J})$.

"El derecho natural a la vida es supremo sobre cualquier otro derecho que se le contraponga", señalan los opositores, y con ello se advierte de nuevo un viraje argumental que los lleva a modificar la relación de equivalencia entre ambos derechos, asumida en algún momento de la discusión, por una relación de jerarquía en la que prevalece el derecho a la vida y que se mantendrá en las participaciones de los opositores a la reforma hasta el final del debate.

\section{c) Los diputados se confrontan}

En la gráfica 1 se ilustra la cantidad de relaciones lógicas establecidas entre pares de argumentos pivote y su distribución por tipo de relación. Como se observa, la mayor cantidad de relaciones entre argumentos son las de oposición, con lo que se reitera el carácter polémico de los debates. Se manifiestan desacuerdos 


\section{Diagrama 1}

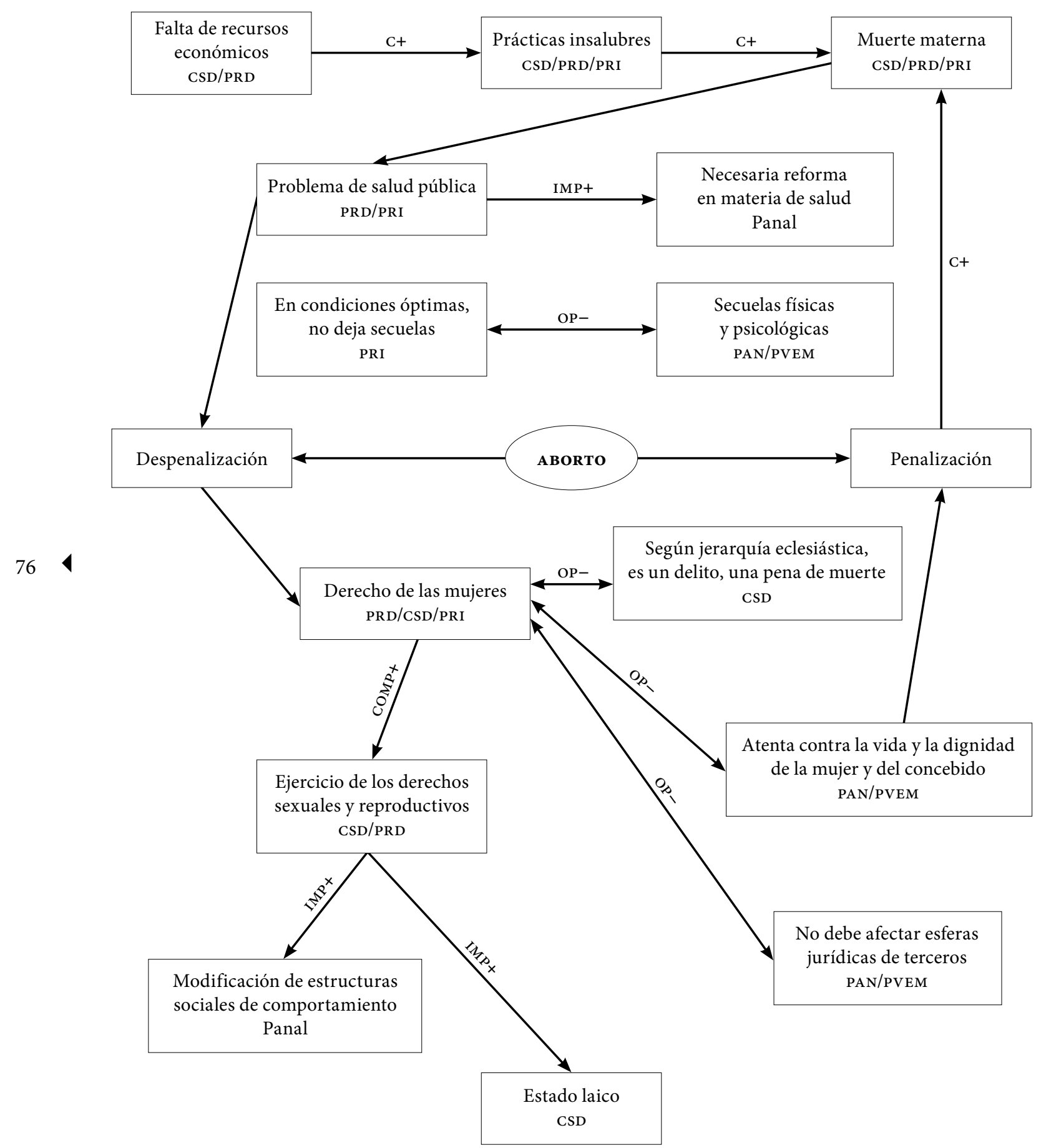


entre bloques en la construcción argumentativa de los siguientes objetos discursivos: "aborto", "conflicto de derechos", "conflicto moral-derecho", "criterio de 12 semanas", "dictamen", "reforma", "laicidad", "pensamiento liberal", “PRD", "referéndum", "soluciones", "vida”. De las 38 construcciones encontradas, sólo nueve quedan establecidas por un mismo grupo parlamentario - cuyas especificidades desarrollaremos más adelante-. El resto surge de la confrontación entre argumentos de legisladores de grupos parlamentarios que se adhieren a bloques contrarios. La manera de construir el objeto "aborto" hace que emerjan desavenencias entre los legisladores en cuanto a las formas de definirlo y los efectos que se derivan de su práctica:

- (CSD/PRD/PRI) Se trata de un derecho que es al mismo tiempo básico y exclusivo de las mujeres / (PAN/ PVEM) Vulnera el derecho a la paternidad (OP).

- (CSD) El aborto es un derecho reproductivo de las mujeres / (PAN) Elimina el derecho a nacer (OP).

- (PAN) Provoca daño físico y psicológico a la mujer que se lo practica / (PRI) Está comprobado que un aborto bien realizado no dejará ninguna secuela en la salud de la mujer (OP).

- (CSD) Aborto legal, menos muertes / (PAN) Aborto legal no combate la muerte de las mujeres (OP).

Así, los oradores enfrentan los derechos de las mujeres con los de los hombres y con los del concebido, invocan el discurso científico para argumentar la presencia o ausencia de daños físicos y psicológicos ocasionados por la práctica del aborto - sin remitir a las fuentes de donde se obtiene la informacióny apoyan o rechazan la despenalización según los índices de mortalidad materna. Otro asunto proclive al surgimiento de la polémica es aquel relacionado con la vida en los siguientes aspectos:

a) El inicio de la vida

- (pAN) Existe una persona desde el momento de la concepción / (Panal/PRD) Antes de las 12 semanas de gestación se trata científicamente de un embrión y no de un individuo biológico $y$ mucho menos de una persona (oP).

b) El respeto a la vida

- (PAN) Defendemos los huevos de tortugas porque en ellos hay vida / (PRD) Es incongruente defender la vida de los animales y alimentarse de productos que atentan contra sus vidas (OP).

c) El feto como ente autónomo

- (PAN/PVEM) El embrión humano no es parte del cuerpo de la madre, constituye una vida autónoma e independiente / (PRD) El feto no puede ser un actor desvinculado de la madre (OP).

d) El concebido como sujeto acreedor de derechos

- (PAN/PVEM) Todo concebido es sujeto acreedor de derechos / (PRI) De acuerdo con diversos juristas nuestra Carta Magna señala que se considera un individuo con capacidad jurídica hasta el momento de nacimiento (OP).

En lo que respecta al dilema surgido por las valoraciones diferenciadas hacia los dos derechos en juego: el derecho a decidir, que implica la libertad y la autodeterminación de las mujeres, y el derecho a la vida, hay argumentos contrapuestos en el sentido de que mientras los opositores - de los grupos parlamentarios del PAN y del PVEM- consideran el derecho a la vida como primero y fundamental, los promotores - concretamente, el grupo parlamentario del Panal- le oponen a éste la libertad como bien jurídico y el más fundamental de los derechos. Por otra parte, cuando diputados del Panal y del PRD exigen respeto al derecho de la mujer a decidir sobre su cuerpo, sus adversarios políticos -el bloque opositor- acusan limitaciones a la libertad de la mujer al señalar que ésta daña los derechos de un tercero, en este caso, el producto del embarazo. Todas estas construcciones argumentales guardan relaciones de oposición y se plantean como una confrontación entre bloques: legisladores de ambos grupos se enfrentan discursivamente. No obstante, también ocurren casos de relaciones de oposición entre argumentos esbozados por oradores de un mismo grupo 
parlamentario. En estos casos no se trata de cambios o inconsistencias en las posturas políticas, sino en predicaciones contrarias de un mismo objeto enunciadas casi simultáneamente para resaltar o afianzar una de ellas. Deliberadamente, pues, se expresan las oposiciones entre:

- (CSD) El aborto como derecho reproductivo vs. el aborto como delito o pena de muerte como es concebido por la Iglesia Católica.

- (PAN) El derecho a la libertad como prioridad de la mayoría parlamentaria $v s$. el derecho a la vida como máximo bien tutelado constitucionalmente.

- (PRD) La autonomía individual como espacio en que se desarrolla la moralidad vs. la convivencia y orden social como espacio de acción de la legalidad.

- (PAN) La eficacia de la reforma para combatir la clandestinidad $v s$. la ineficacia de la reforma para combatir la insalubridad.

- (PRI) El enfrentamiento entre las leyes del Estado $v s$. las leyes de la Iglesia.

Estas oposiciones marcan posturas contrarias en la conceptualización de un objeto. Tal es el caso del aborto como derecho o como delito, el conflicto entre moralidad y legalidad como parámetros para la evaluación de la reforma y la confusión entre los ámbitos de acción de las leyes del Estado y las leyes religiosas como fuentes de sanción de las conductas de los ciudadanos. Otra forma de marcar oposiciones es revelar incongruencias entre el discurso y el comportamiento político de los adversarios. Hacer aflorar las contradicciones sirve como posible estrategia de refutación de algún argumento sostenido por los contrarios. A continuación enlistamos los casos de este tipo encontrados en el corpus:

- (CSD/PRD) El aborto es un derecho reproductivo de las mujeres / (PAN/PVEM) Resulta incongruente que si la iniciativa pretende otorgar a las mujeres el derecho a decidir, también debería dárseles el derecho a opinar por medio de un referéndum (OP).
- (PAN) El PRD está a favor de los derechos de las mujeres / (PAN) Sólo 17\% de las curules del PRD son ocupadas por mujeres y todos los jefes delegacionales de ese partido son hombres (OP).

- (PAN) Acción Nacional propone un referéndum para consultar a la ciudadanía / (PRI) El Partido Acción Nacional siempre estuvo en contra de las consultas públicas que realizaba el exjefe de Gobierno porque decían que eran costosas y, lo principal, que para eso el pueblo había votado por sus representantes populares y ellos eran los representantes de ese pueblo (OP).

- (PAN) Educación e información como verdadera solución / (PRD) Los diputados del PAN se opusieron a la educación sexual, no quieren que se informe sobre anticonceptivos, se escandalizan por la promoción del condón (OP).

De acuerdo con el grupo parlamentario del PAN, el PRD se dice impulsor de la democracia participativa, pero se niega a su ejercicio al rechazar el referéndum; se dicen defensores de los derechos de las mujeres, pero promueven inequidad en la ocupación de cargos públicos entre sus militantes hombres y mujeres; incluso se oponen -a los ojos de los impulsores del referéndum - a que sea escuchada la voz de las mujeres mediante mecanismos de participación ciudadana. Los grupos parlamentarios del PRD y del PRI hicieron lo propio al acusar al PAN de haber mantenido siempre una postura contraria a los mecanismos de participación ciudadana en anteriores legislaturas y ahora erigirse como sus principales defensores, lo que contraviene sus argumentos pasados del costo de un referéndum y de su papel como representantes populares para oponerse a ellos sin tener la necesidad u obligación de consultar a los ciudadanos. Asimismo, los promotores de la reforma - concretamente el PRD-, a pesar de estar a favor de que la educación y la información sean las principales soluciones al aborto como problema de salud, utilizan este argumento enunciado por los legisladores del PAN para evidenciar su incongruencia ideológica, pues la educación implica la información 
Diagrama 2

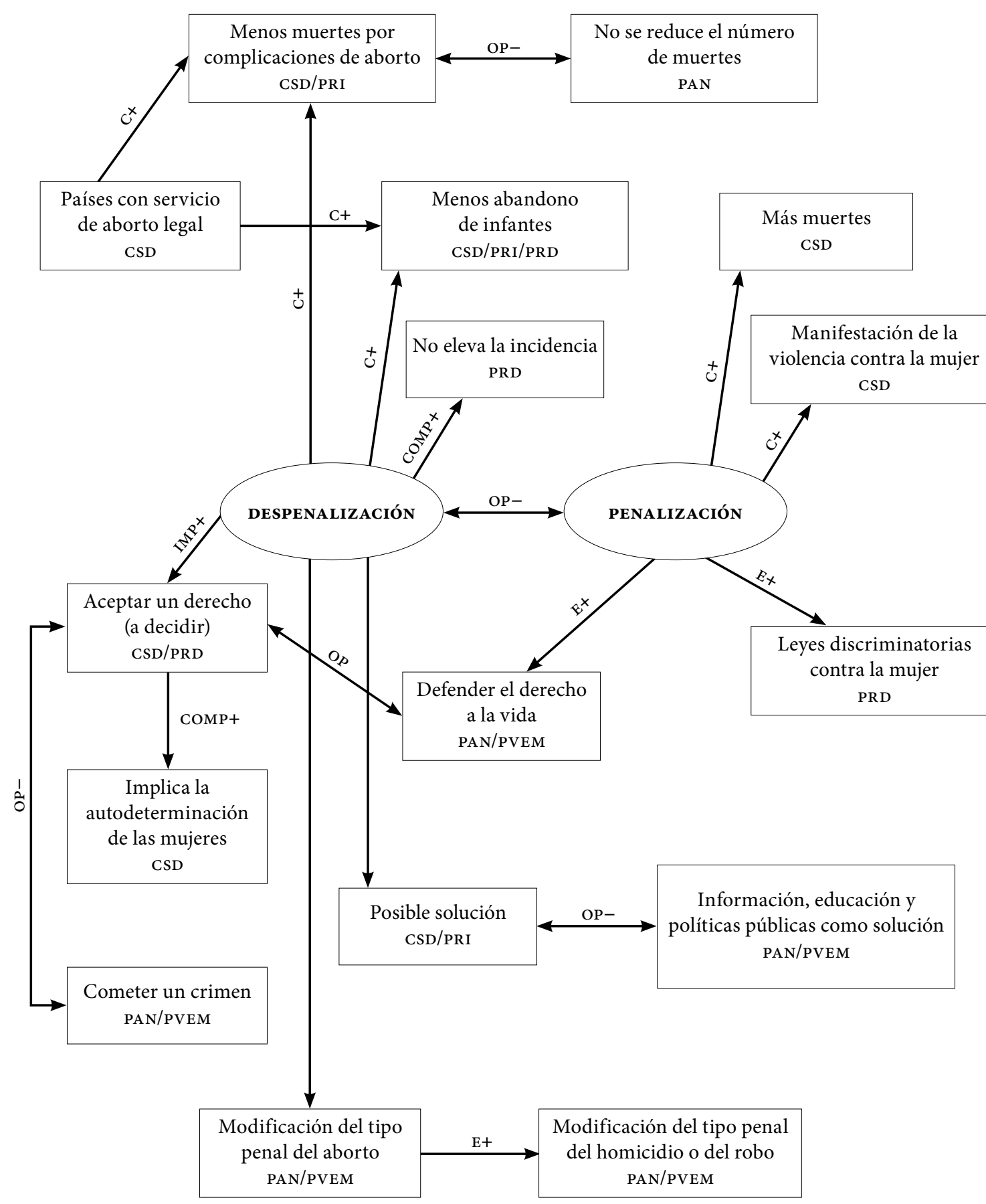




\section{Diagrama 3}

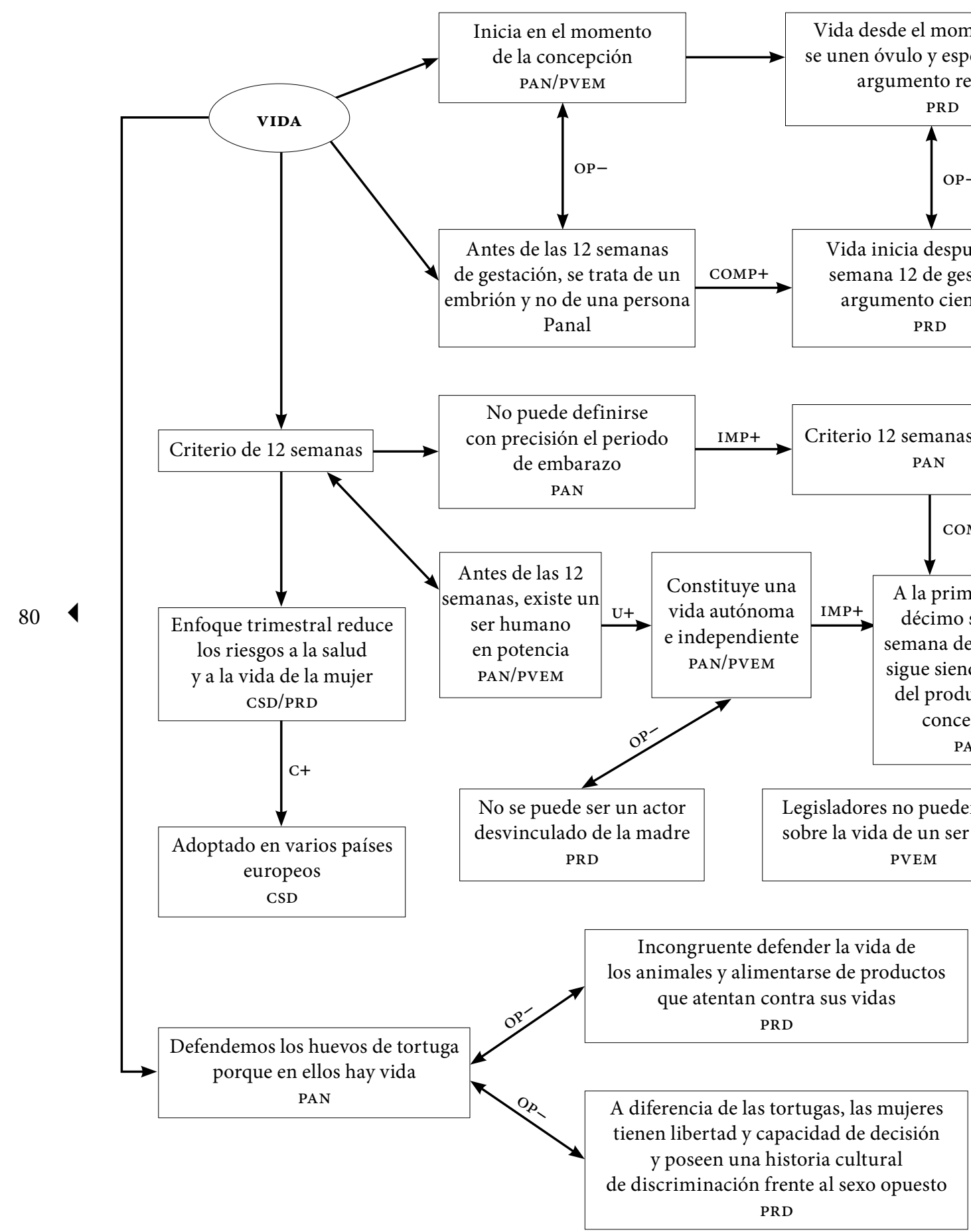


amplia sobre temas sexuales, entre ellos el uso de anticonceptivos, hacia los que los panistas han expresado su rechazo - en el sentido de incorporar la educación sexual y promover estos métodos en niños y jóvenes que cursan niveles educativos básicos-.

Como hemos revisado, son varias las relaciones que se establecen entre argumentos generando un tejido discursivo complejo en el que confluyen varios objetos, predicaciones en diferentes sentidos y enunciadores de todos los grupos parlamentarios. Ahora bien, sobre un mismo objeto discursivo se tejen distintas relaciones, que se combinan para delinear una estrategia política. Los diagramas que presentamos condensan los mismos resultados expuestos anteriormente, pero ahora ilustrando cómo ocurre este juego de asociaciones múltiples a propósito de un solo objeto discursivo y la participación de distintas líneas ideológicas y políticas en la construcción del mismo. Las flechas indican relaciones entre argumentos y las abreviaturas sobre ellas, el tipo de relación establecida. Sobre el objeto "aborto" se construyen una serie de predicaciones que se vinculan directamente con las acciones a debate: despenalizar o mantener la penalización. Esta primera relación apunta al proceso que se está discutiendo: la aprobación de la reforma, y las demás relaciones que se van configurando parecen estar subordinadas a ella y delinear una lógica general de disyunción en la que cada argumento se vuelca hacia el apoyo o el rechazo de alguna de las dos opciones (véanse diagramas 1 y 2 ).

El debate alrededor de la vida (véase diagrama 3) básicamente se nutre con las distintas estimaciones de cuándo comienza en el caso de un embarazo. Existe un desfase argumental por el traslape de proposiciones: unas que calculan el principio de la vida desde la concepción y otras que se refieren al inicio de la vida humana como conjunción de un desarrollo humano y una relativa madurez psíquica. Todo esto trae como consecuencia un debate donde priman las relaciones de oposición, que no necesariamente deberían considerarse excluyentes dado que se trata de objetos distintos - vida orgánica y vida humana-, pero que los oradores así construyen y con ello avivan la polémica sobre el asunto. Los diagramas 4 y 5 ilustran las confrontaciones entre los bloques parlamentarios en el terreno de la acción política: el referéndum como mecanismo de participación ciudadana es una propuesta que permite a sus impulsores - legisladores del PAN y del PVEMla explotación de un recurso democrático, de inclusión ciudadana, para oponerlo a la decisión calificada de autoritaria por los diputados de PAN de la aprobación de la reforma por una mayoría absoluta, que se corresponde con la conformación del órgano legislativo. Pero también sirve a sus detractores para mostrar inconsistencias y para descubrir estrategias políticas en los diputados del partido que lo está promoviendo. Al debate sobre el referéndum se suman los ataques discursivos entre ambos bloques en torno a las oposiciones: a) pensamiento liberal $v s$. pensamiento conservador; b) ideas progresistas vs. ideas retrógradas, y c) actuar democrático vs. actuar autoritario.

\section{CONCLUSIONES}

A manera de conclusión podemos afirmar que los debates parlamentarios se entienden y se explican como una serie de discursos que fluyen de manera secuencial y en cuya configuración pesa de forma significativa la construcción lógica. Ésta añade al poder argumentativo de las proposiciones una dimensión reticular en la que se advierten nexos entre argumentos, los cuales potencian la estructura argumentativa e incorporan y son parte a la vez de un contexto, de una dimensión formal propia del ritual que tiene lugar en el acto de habla y de una confrontación política en la que se advierten aliados y adversarios. En función del reconocimiento de estas premisas, los argumentos valen tanto por la fuerza racional de su contenido como por el potencial estratégico de su ubicación en el entramado discursivo. El análisis de los argumentos dio cuenta de la 
Diagrama 4

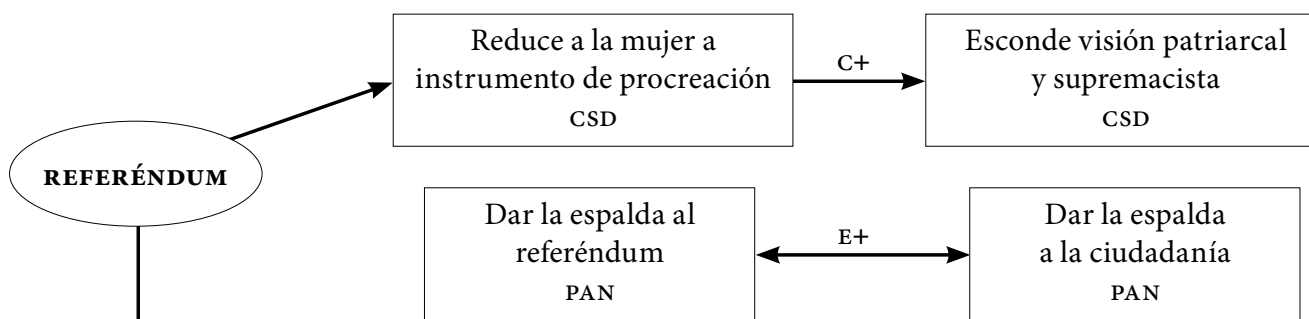

COMP+

Desestimar firmas que

solicitaron el referéndum

PAN
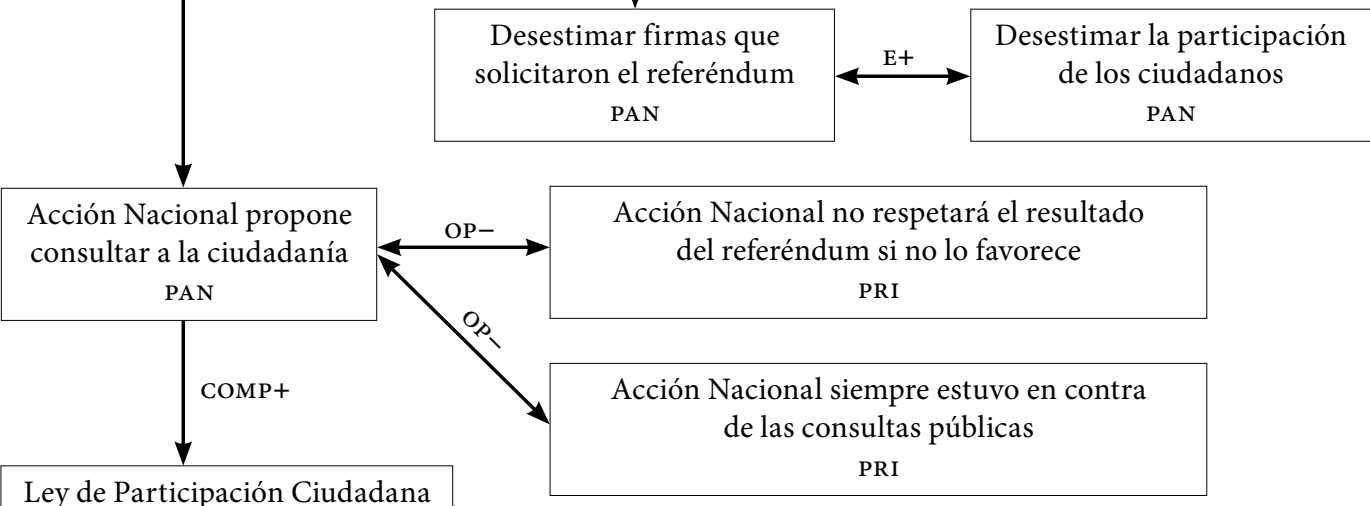

contempla el referéndum como instrumento legal y legítimo

PAN

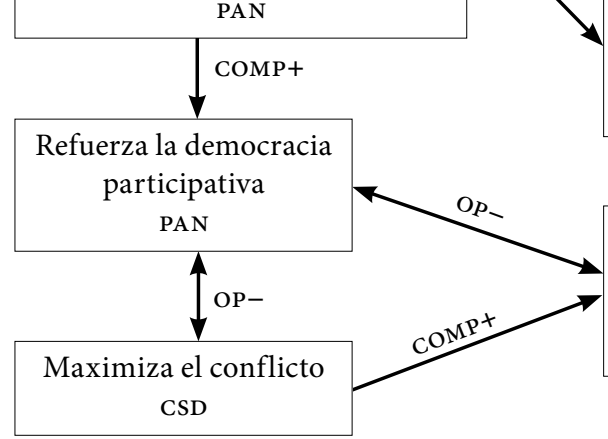

Ley de Participación

Ciudadana no garantiza que

el referéndum pueda estar

exento de manipulaciones

CSD

Los regímenes totalitarios

y dictatoriales son los más

consumidores

CSD
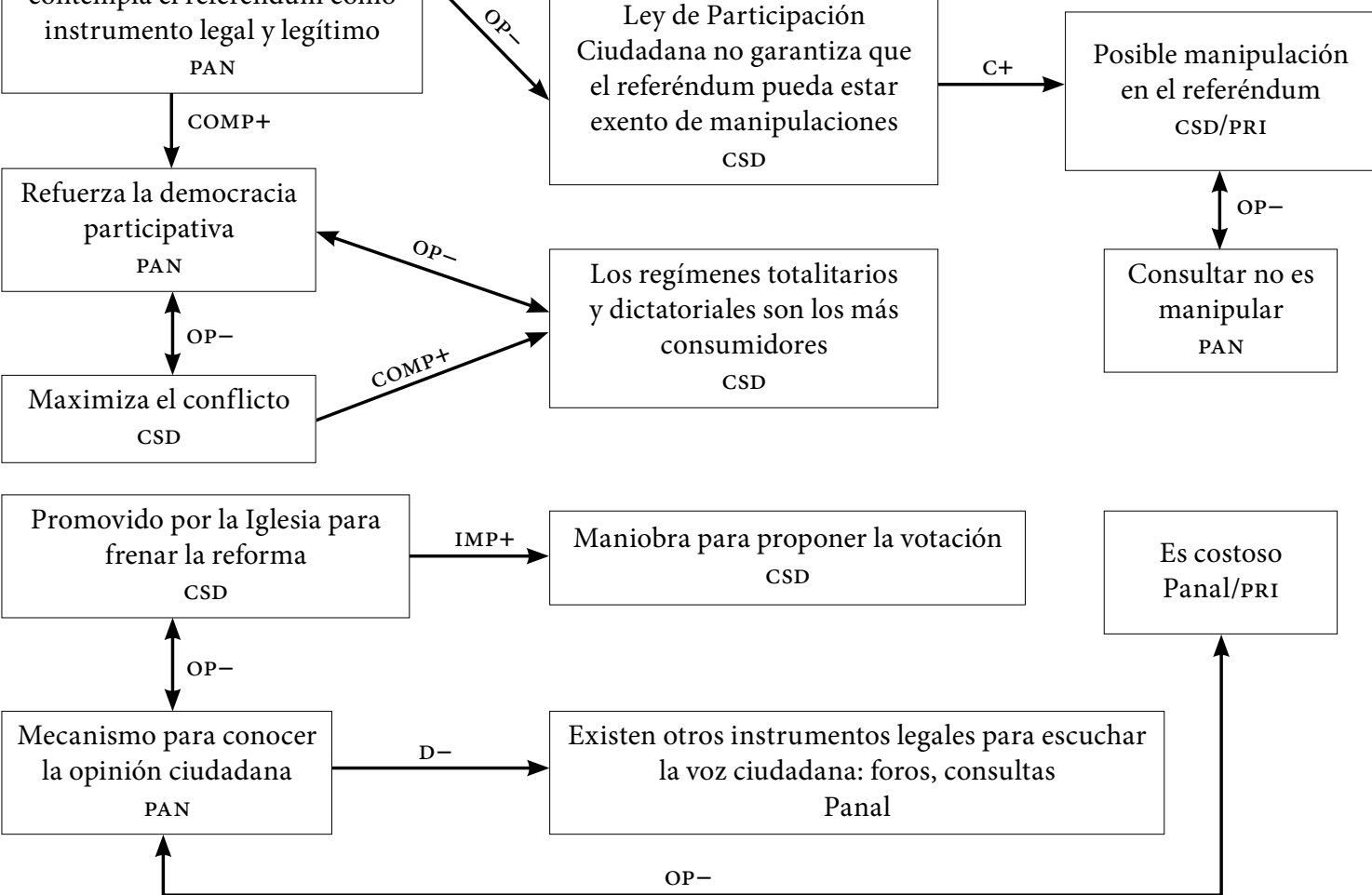
Diagrama 5
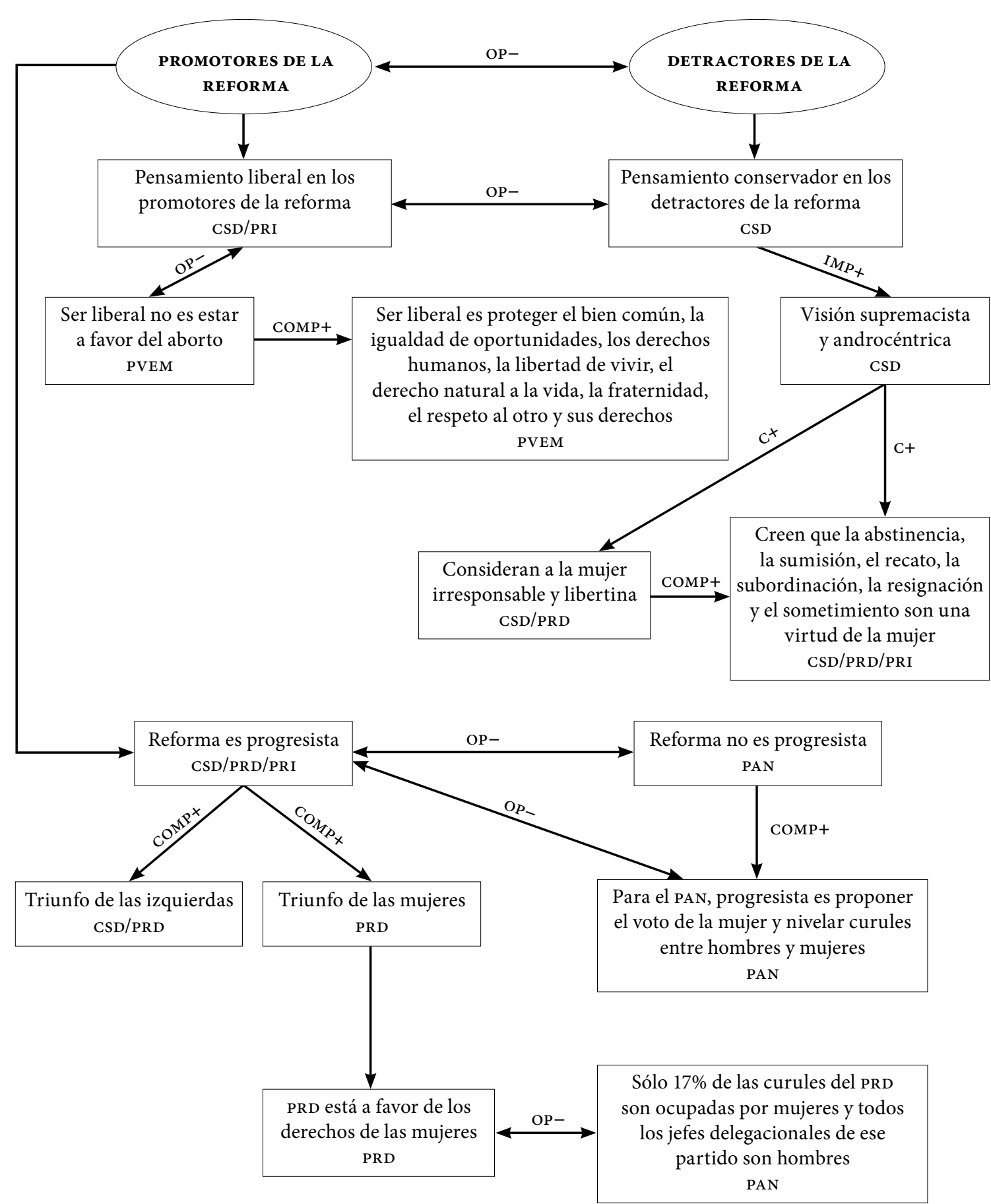
disputa verbal que tuvo lugar en el recinto parlamentario, de las confrontaciones personales, colectivas e ideológicas que ahí se suscitaron; pero también del establecimiento de alianzas y solidaridades, de la creación o recreación de matrices discursivas - quizá de tradición histórica, quizá coyunturales- que contribuyeron, y siguen contribuyendo, a alimentar el debate sobre el aborto y a establecer un terreno potencialmente propicio, fértil y de gran densidad discursiva, sobre el cual, a partir de un tema polémico, se dirimen o acentúan conflictos políticos.

\section{BIBLIOGRAFÍA}

Carbó, Teresa, 1996, El discurso parlamentario mexicano entre 1920 y 1950. Un estudio de caso en metodología de análisis de discurso, Centro de Investigaciones y Estudios Superiores en Antropología Social, El Colegio de México, México.

Foucault, Michel, 1988, "El sujeto y el poder", en Hubert Dreyfus y Paul Rabinow, Michel Foucault: más allá del estructuralismo y la hermenéutica, Universidad Nacional Autónoma de México, México.

Giménez, Gilberto, 2008, El debate político en México a finales del siglo Xx. Ensayo de análisis del discurso, Instituto de Investigaciones Sociales-Universidad Nacional Autónoma de México, México.

-, 1981, Poder, Estado y discurso. Perspectivas sociológicas y semiológicas del discurso político-jurídico, Universidad Nacional Autónoma de México, México.

Grize, Jean Blaise, 1990, Logique et Langage, Ophrys, París. Gutiérrez, Silvia, 1989, “La argumentación”, en Argumentos. Estudios Críticos de la Sociedad, núm. 8, pp. 7-20.

Montes, Rosa y Patrick Charaudeau, 2009, El "tercero". Fondo y figura de las personas del discurso, Benemérita Universidad Autónoma de Puebla, México.

Pêcheux, Michel, 1978, Hacia el análisis automático del discurso, Gredos, Madrid.

Plantin, Christian, 2005, La argumentación, Ariel, Barcelona.

Salgado, Eva, 2003, El discurso del poder. Informes presidenciales en México (1917-1946), Centro de Investigaciones y Estudios Superiores en Antropología Social, Miguel Ángel Porrúa, México.

Vignaux, Georges, [1976] 1986, La argumentación. Ensayo de lógica discursiva, Hachette, Buenos Aires. 